\title{
Simulations of spawning habitats for brown trout in an Alpine river reach using a two- stage multivariate fuzzy-logical approach
}

\author{
Markus Noack, Johannes Ortlepp \& Silke Wieprecht \\ Keywords: fuzzy logic, habitat modelling, spawning habitat, brown trout, Alpine rivers
}

\section{Abstract}

The availability of suitable spawning habitats for gravel-spawning fish is an important indicator for Alpine river reaches regarding hydro- and morphodynamic components of fluvial ecosystems. This paper presents advances in habitat modelling techniques of suitable spawning habitat conditions for brown trout (Salmo trutta) by applying multivariate fuzzy-logical habitat modelling in combination with a three-dimensional numerical sediment-transport model. The fuzzy-logical approach considers multiple particle size classes to evaluate the suitability of sediment characteristics (sediment spawning index, SSI). It is then combined with hydraulic characteristics to compute spawning habitat suitability $\left(\mathrm{HSI}_{\text {spown }}\right)$. The study site is part of the River Spoel in the Swiss National Park in the Central Alps of Switzerland. The modelling approach was applied to two spawning seasons (2009 and 2010) and provides information about the spatial distribution of suitable spawning habitats. The simulated results indicate a good model performance when comparing the simulation results with observed spawning redds. The predictability of the modelling approach allows further investigations into new management scenarios to improve the hydro- and morphodynamic situation in the River Spoel and to increase the availability of suitable spawning habitats for brown trout.
Profile

Protected area

Swiss National Park

Mountain range

Alps

Country

\section{Switzerland}

\section{Introduction}

The relevance of investigating riverine habitats is spelled out in the EU Water Framework Directive (WFD) because, in addition to water quantity and water quality, the habitat is one key component in the integrated approach of the WFD on fluvial ecosystems (Conallin et al. 2010). In general, a habitat is defined as the environmental surroundings composed of multiple dimensions representing biotic and abiotic components related to the use of a location by an organism (Beyer et al. 2010). This definition provides the basis for aquatic habitat simulation tools to model the biotic response of indicator species to varying environmental factors using physical-biota relationships. Based on the similarity of existing and preferred conditions of aquatic organisms, an estimate of habitat quality can be assigned to a specific location. The classic approach of qualifying and quantifying habitats to estimate habitat indices defines an optimum range of abiotic conditions for indicator species (Leclerc et al. 2003). The most common index to describe the biological response to abiotic attributes is the habitat suitability index (HSI) which ranges from 0.0 (unsuitable) to 1.0 (most suitable).

Recently several habitat modelling studies have been performed to simulate fish spawning habitats (e.g. Moir et al. 2005; Schneider et al. 2007). The majority of them use the most applied and so-called conventional habitat variables in fish habitat modelling: flow velocity, water depth and dominant substratum (Heggenes 1988).
Only one study (Mouton et al. 2008) considered two particle size classes (fine and medium-sized gravel) for simulating spawning habitats of grayling. However, this kind of habitat description might not be sufficient to describe the habitat requirements for the spawning process of gravel-spawning fish. In particular, single variables used to describe the sediment characteristics have a limited capability to fully meet the spawning requirements. According to Dirksmeyer \& Brunotte (2009), parameters that have been developed to assess the suitability of spawning gravels, such as the content of fine sediments, the mean geometric diameter or the Fredle-Index, are not on their own sufficient to describe all relevant functions of a particle size distribution for spawning. For example, sites with accumulated fines are avoided as those locations might not provide sufficient oxygen supply to deposited eggs, but the content and size of cobbles might also be limiting as the female must be able to move gravels to excavate the redd (Kondolf et al. 2008).

The objective of this study is to present a habitatbased modelling approach for spawning habitats of brown trout (Salmo trutta) using a multivariate twostage fuzzy-logical approach which considers multiple particle size classes to account for the high sediment requirements in the modelling process of the spawning habitats. Therefore a 3D sediment-transport model (SSIIM3D, Olsen 2013) is applied to simulate the hydro- and morphological data in high spatial resolution and to provide detailed information about hydraulic and sedimentary habitat characteristics. Furthermore, 


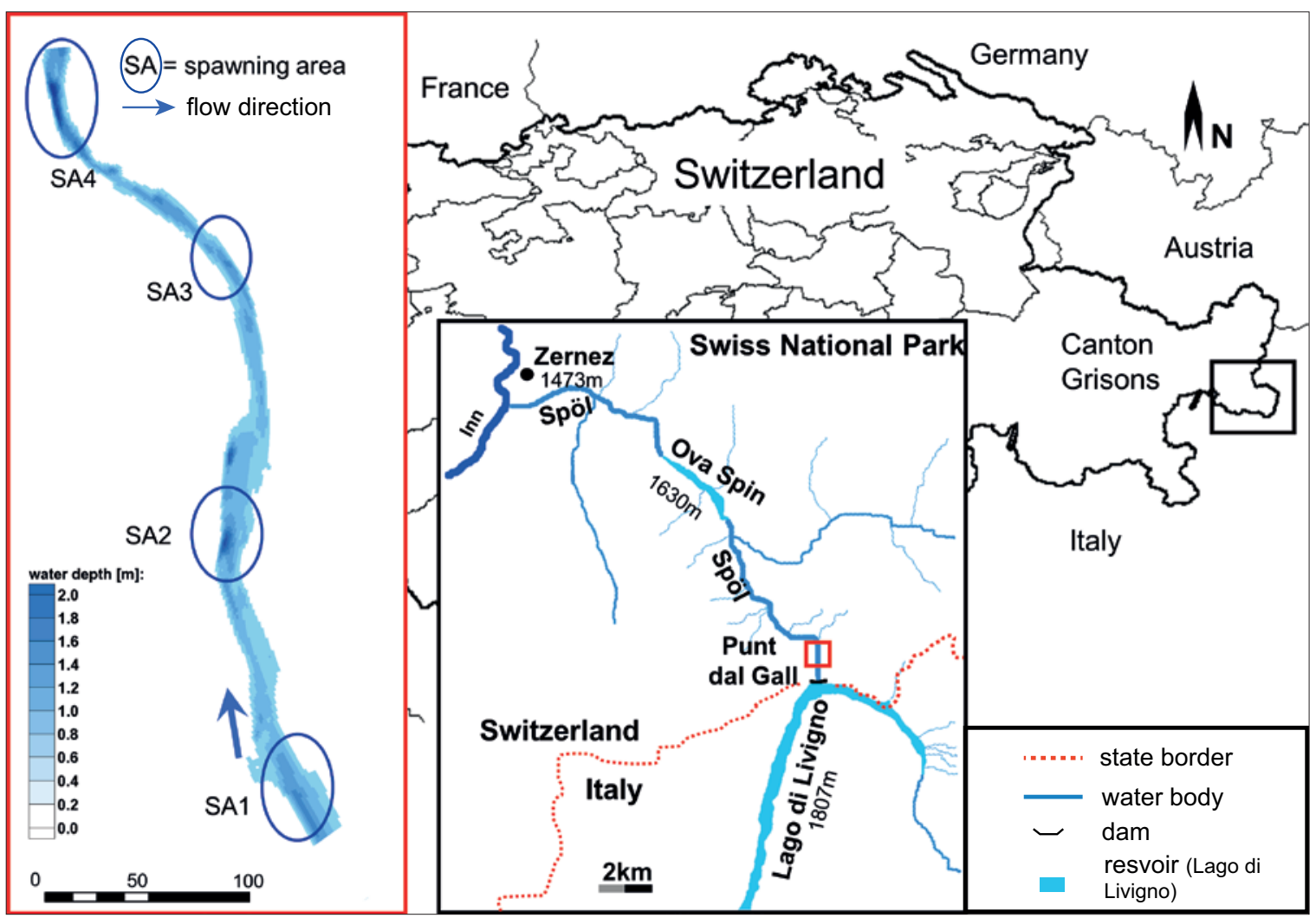

Figure 1 - Swiss National Park with the River Spoel in Switzerland and the chosen study site between the Ova Spin and Lago di Livigno reservoirs. The circles ( $S A 1-S A 4)$ represent the major spawning sites.

the habitat modelling system CASiMiR (Schneider 2001; Noack et al. 2013) is applied with its fuzzy-modelling technique to link abiotic attributes with habitat requirements. The proposed modelling concept is applied at the River Spoel in the Swiss National Park and the results are evaluated against counted spawning redds for two spawning seasons.

\section{Study area}

The investigations for spawning grounds of brown trout were conducted in the River Spoel in the Swiss National Park (SNP) in the Central Alps of Switzerland $\left(46^{\circ} 66^{\prime} \mathrm{N}, 10^{\circ} 19^{\prime} \mathrm{E}\right)$. The SNP stretches across a total area of $170.3 \mathrm{~km}^{2}$, with altitudes ranging from $1400 \mathrm{~m}$ to $3174 \mathrm{~m}$. The study site is located between the Punt dal Gall (Lago die Livigno) and Ova Spin dams (reservoir Ova Spin) and is characterized by a regulated flow throughout the year. The study site has a length of approximately $400 \mathrm{~m}$ with an average width of $15 \mathrm{~m}$ and a slope of $1.8 \%$. Given hydropower operations, the natural mean annual flow of 6.6$12.2 \mathrm{~m}^{3} / \mathrm{s}$ is reduced to a constant flow of $1.44 \mathrm{~m}^{3} / \mathrm{s}$ (summer) or $0.55 \mathrm{~m}^{3} / \mathrm{s}$ (winter). As a result of this flow regulation, the River Spoel has lost its mountain stream character of regularly occurring flood events that induce bed alterations and sediment mixing processes. To enhance hydromorphological heterogeneity, an experimental flood programme started in the year 2000 (Scheurer \& Molinari 2003) with the objective of flushing out the accumulated fine sediments, reducing the dense coverage of mosses and providing suitable reproduction areas for the brown trout, the only fish species that lives and reproduces in the River Spoel (Ortlepp \& Muerle 2003). Figure 1 provides an overview of the study area and the investigated study site. The circles SA1 to SA4 represent the major spawning areas derived from mapping surveys from 2003 to 2010 by the local fishing authority. These yearly surveys provide counts of spawning redds at different locations along the River Spoel allowing for a detailed evaluation of the proposed modelling concept. For the spawning season 2009 a total number of 43 redds were counted in the study site, in the 2010 season the total number was 48 .

\section{Methods}

The two-stage multivariate fuzzy-logical approach

During reproduction a proper mix of cobbles, pebbles, gravels and sand is required for spawning (Kondolf et al. 2008). Therefore, in a first step, the numerically simulated particle size distributions (10 particles sizes) are classified into four particle size ranges: sand (<2 mm), gravel (2-31 $\mathrm{mm})$, pebbles (31-64 $\mathrm{mm})$ and cobbles $(>64 \mathrm{~mm})$. These particle size classes were combined via a multivariate fuzzy-logical approach to a sediment spawning index (SSI) to evaluate the suitability of the particle size distribution for spawn- 


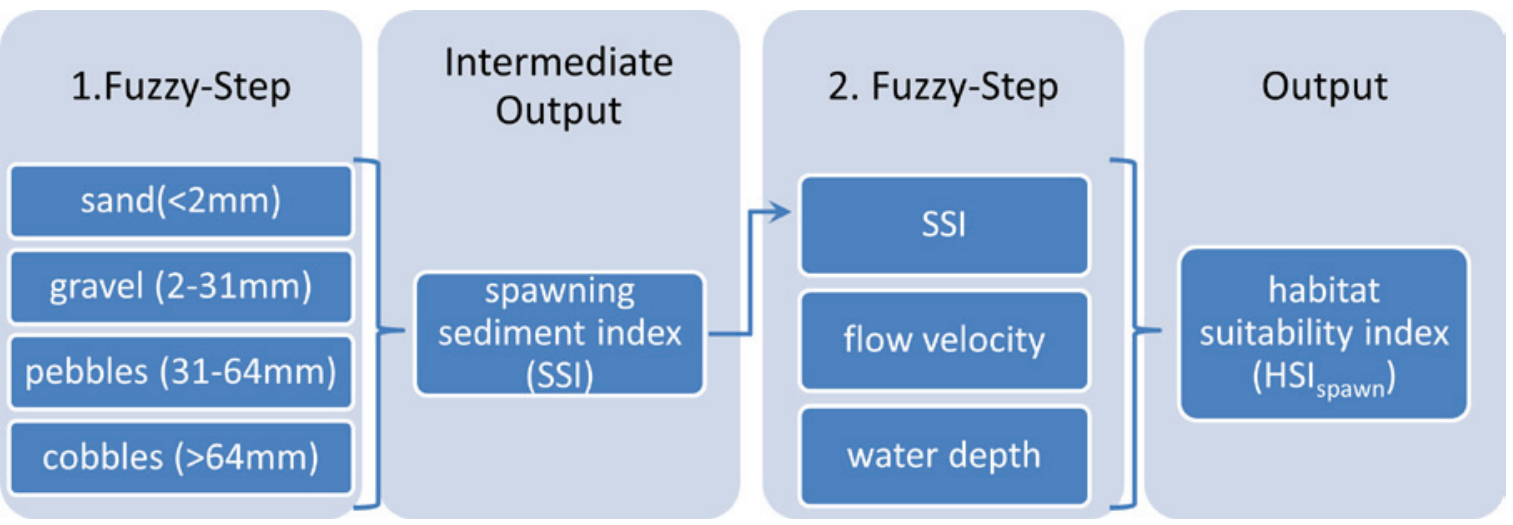

Figure 2 - Two-stage furay-logical approach to simulate the spawning habitat suitability. In a first step the spawning sediment index (SSI) is computed using multiple particle size classes. In a second step the SSI is combined with hydraulic characteristics to simulate the habitat suitability for spawning (HSI $I_{\text {spawn }}$ ).

ing purposes. The latter is important to account for spawning habitat requirements on river bed sediment characteristics, such as the maximum amount of fine material (e.g. Louhi et al. 2008) or the maximum particle size a female is able to move during the digging in of redds (Wooster et al. 2008). The second step considers the varying hydraulic conditions to account for sufficient manoeuvrability during the spawning process (e.g. Armstrong et al. 2003). Therefore two parameters are chosen: water depth and flow velocity. Figure 2 represents the two-stage fuzzy-logical approach to simulate the spawning habitat suitability (HSI $\left.{ }_{\text {spawn }}\right)$ for brown trout.

A literature study was performed to define the habitat requirements for spawning. Information on the suitability of the four different particle size classes was obtained from Louhi et al. (2008) and Soulsby et al. (2001) for the sand content, information on the gravel and pebble content from Fluskey (1987) and Mull \& Wilzbach (2007), and information on the maximum moveable particle size (cobbles) from by Kondolf \& Wolman (1993) and Wooster et al. (2008). For the hydraulic characteristics we consulted the studies of Armstrong et al. (2003) and Louhi et al. (2008). In addition to the literature values the habitat requirements were developed from long-term studies (10 years) on the River Spoel brown trout population (Ortlepp, unpublished). This procedure ensures the application of the best available expert-knowledge.

\section{Fuzzy sets and fuzzy rules}

The first step in fuzzy modelling is the fuzzification of the chosen habitat variables by defining overlapping membership functions represented by linguistic terms (e.g. low, medium, high; Figure 3). Values between 0.0 and 1.0 are defined, where 0.0 means that an element does not belong to a membership function and 1.0 means that it belongs entirely. Given the overlapping membership functions, which reflect gradual transitions between parameter classes, the fuzzy theo-

Table 1 - Sample furay rules for the first step in the two-stage furay approach describing the habitat requirements of brown trout regarding the suitability of particle size distributions (SSI) for spawning purposes in the River Spoel.

\begin{tabular}{|l|l|l|l|l|l|l|l|}
\hline & sand & gravel & pebbles & cobbles & SSI & Examples \\
\hline 1 & H & & & & L & rule 1 & IF sand content high THEN SSI low \\
\hline 2 & & & & H & L & rule 2 & IF cobbles content high THEN SSI low \\
\hline 3 & L or M & M & M & L & VH & rule 3 & $\begin{array}{l}\text { IF sand content low or medium AND gravel AND pebble content medium } \\
\text { AND cobbles low THEN SSI very high }\end{array}$ \\
\hline 4 & L or M & M & H & L & H & & L = low, M= medium \\
\hline 5 & M & M & M & M & M & & H = high, VH = very high \\
\hline 6 & M & L & L & M & L & & SSI = sediment spawning index \\
\hline
\end{tabular}

Table 2 - Sample furay rules for the second step in the two-stage furay approach describing the habitat requirements of brown trout regarding the suitability of spawning habitats (HSI spawn in the River Spoel.

\begin{tabular}{|l|l|l|l|l|l|l|}
\hline & SSI & velocity & depth & HSI & \multicolumn{2}{|l|}{ Examples } \\
\hline 1 & L & & & L & rule 1 & IF SSI low THEN HSI \\
\hline 2 & & VL or VH & VL or VH & L & rule 2 & IF velocity AND / OR depth very low or very high THEN HSI \\
\hline 3 & VH & M & M & VH & rule 3 & IF SSI is very high AND velocity AND depth medium HSI \\
\hline 4 & H & M or H & L or M & H & SSI & = sediment spawning index \\
\hline 5 & M & L or M or H & L or M or H & M & HSI & = habitat suitability index for spawning \\
\hline
\end{tabular}



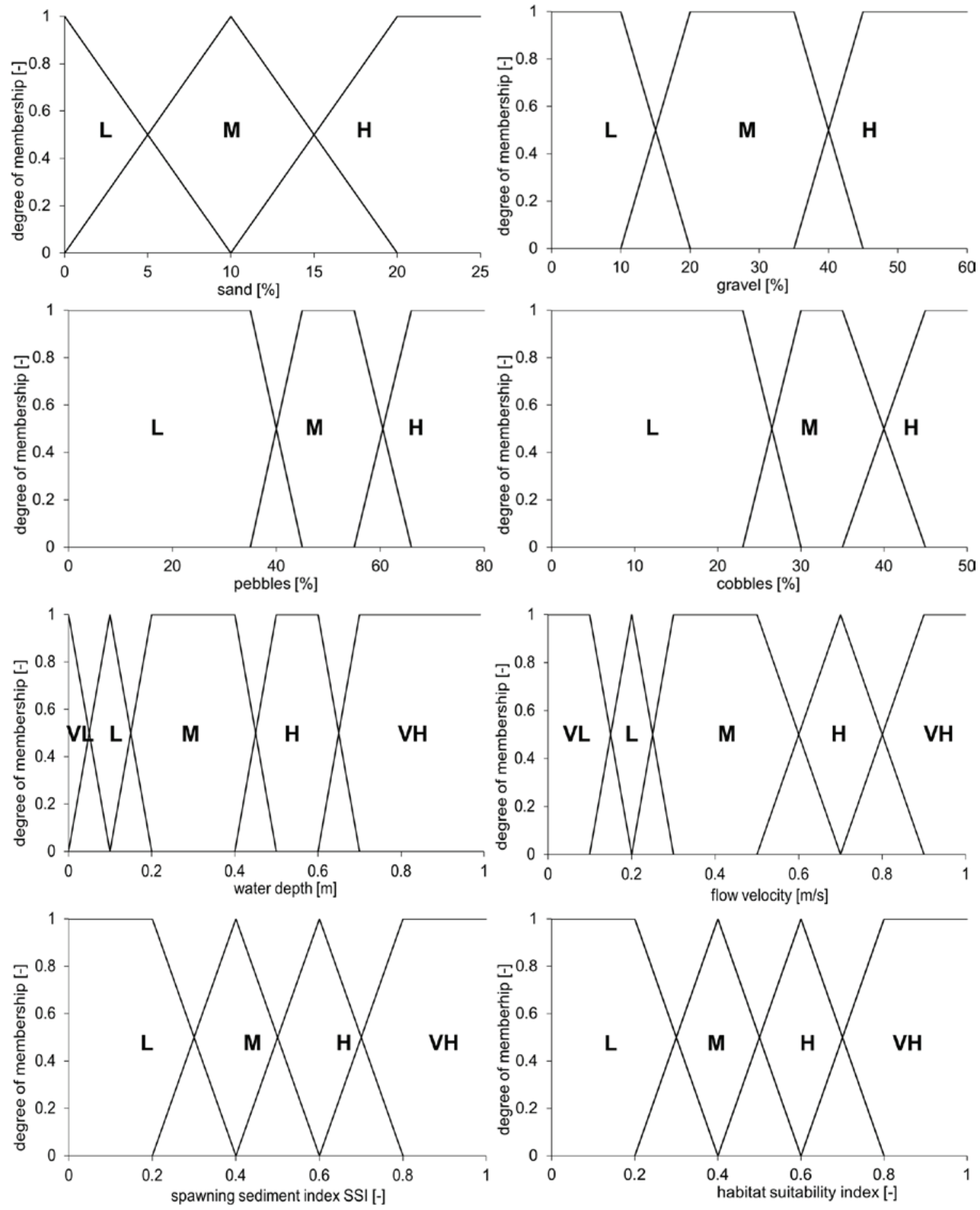

\section{VL=very low $\quad L=$ low $\quad M=$ =medium $\quad H=h i g h \quad V H=$ =very high}

Figure 3 - Fuziification of all applied input and output parameters. Each habitat description variable (input variables) as well as the output variable (SSI, HSI $I_{\text {spun }}$ ) are classified into several membership functions represented by linguistic terms (very low, low, medium, high and very high).

ry allows an appropriate representation of ecological gradients.

After fuzzification the physical-biota relationships must be determined using IF-THEN rules. In general such a fuzzy rule consists of several arguments (habitat variables) building a premise in the first part and a consequence (HSI) in the second part. Table 1 provides an overview of the rule set for computing the sediment spawning index (SSI) based on the content of sand, gravel, pebbles and cobbles.

The rules in Table 1 can be read as follows: a bigh sand content, i.e. higher than $10 \%$ (with maximum 


\section{sediment characteristics}

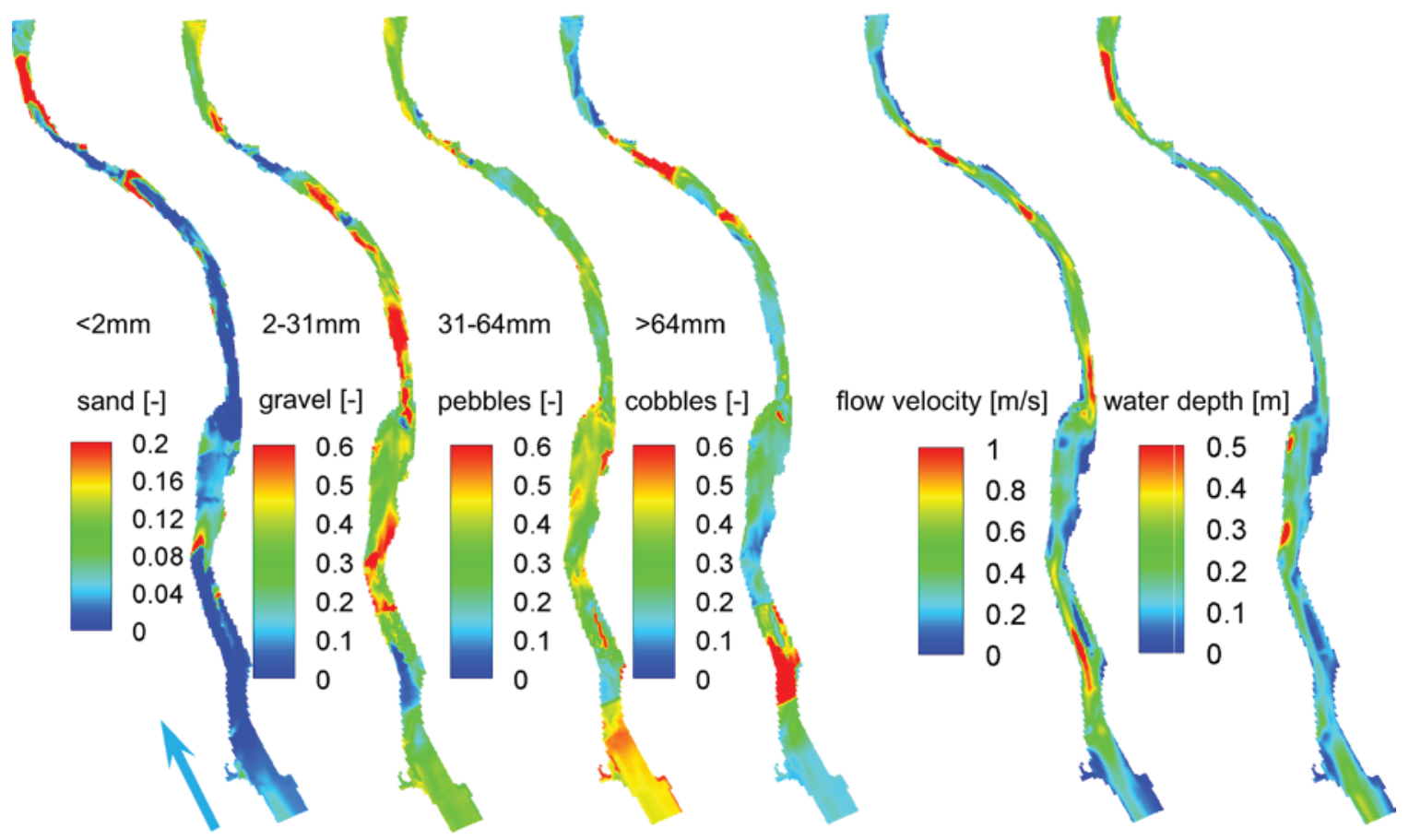

Figure 4 - Spatial distribution of applied habitat variables (based on numerical modelling) to simulate the sediment spawning index (SSI) and the spawning habitat suitability index (HSI spawn $)$ in the spawning season 2009.

degree of membership at 20\%), returns low SSI values because sites with accumulated fine material are not suitable for spawning purposes (rule 1). Similarly, a high cobble content is not suitable and linked to a low SSI value, since a high content of particle sizes $>64 \mathrm{~mm}$ cannot be moved during the digging process (rule 2). A very high SSI value is achieved if the sand content is low or medium and the gravel and pebble content is in the medium membership function and the cobble content is low (rule 3). In this way rules for all possible combinations of membership functions and habitat variables have to be defined, leading to a total number of 81 rules. Given the overlapping, several rules are activated for any input parameter combination. These rules are combined using the maximum-product method (inference system), which return the result as a fuzzy information. A process called defuzzification is applied to transform this fuzzy information back into a crisp number. Therefore, the Centre of Gravity (COG method) is implemented in CASiMiR.

Similar to the rule set for computing the sediment spawning index, a rule set is developed for the habitat suitability for spawning when the SSI value is combined with flow velocity and water depth (Table 2).

A low SSI-value consistently leads to low $\mathrm{HSI}_{\text {spawn }}$ values in all rules because the particle size distribution is not suitable for spawning purposes (rule 1). All rules which have a very low or a very high water depth or flow velocity also lead to low HSI $_{\text {spawn }}$ values since these values represent the upper and lower limits of the hydraulic characteristics for spawning (rule 2). Very high HSI $_{\text {spawn }}$ values are achieved for a combination of very high SSI values with water depths and flow velocities belonging to the medium membership function (rule 3). For the second step of the fuzzy approach the rule set consists of 100 fuzzy rules in total.

The modelling process is performed for each element of the numerical grid. This means that the abiotic characteristics obtained by the hydro- and morphodynamic numerical model are evaluated against the habitat requirements by using the membership function shown in Figure 3 and the fuzzy rule sets listed in Table 1 and Table 2 to get at spatial distribution maps of SSI and HSI values.

Numerical modelling of hydro- and morphodynamic processes

To obtain the required input variables for habitat modelling the three-dimensional numerical sediment-transport model SSIIM3D was applied for two spawning seasons (2009 and 2010). The numerical grid was discretized by $400 \times 40 \times 5$ cells, leading to a total number of 80000 cells and a spatial resolution of roughly $1 \mathrm{~m}$ x $1 \mathrm{~m}$. The numerical model was calibrated using the measured bed levels and particle size analyses directly before and after flooding in 2009 (03.09.2009) and validated on data from flooding in 2010 (01.07.2010) to ensure proper model functionality. In both cases the simulated time periods include the latest artificial flood and the end of the spawning period. In both simulation periods the regulated discharges for summer $\left(1.44 \mathrm{~m} / \mathrm{s}^{3}\right)$ and winter $\left(0.55 \mathrm{~m}^{3} / \mathrm{s}\right)$ were considered. Flooding was done in both periods with the same maximum discharge $\left(40 \mathrm{~m}^{3} / \mathrm{s}\right)$ and a 
spawning period 2009

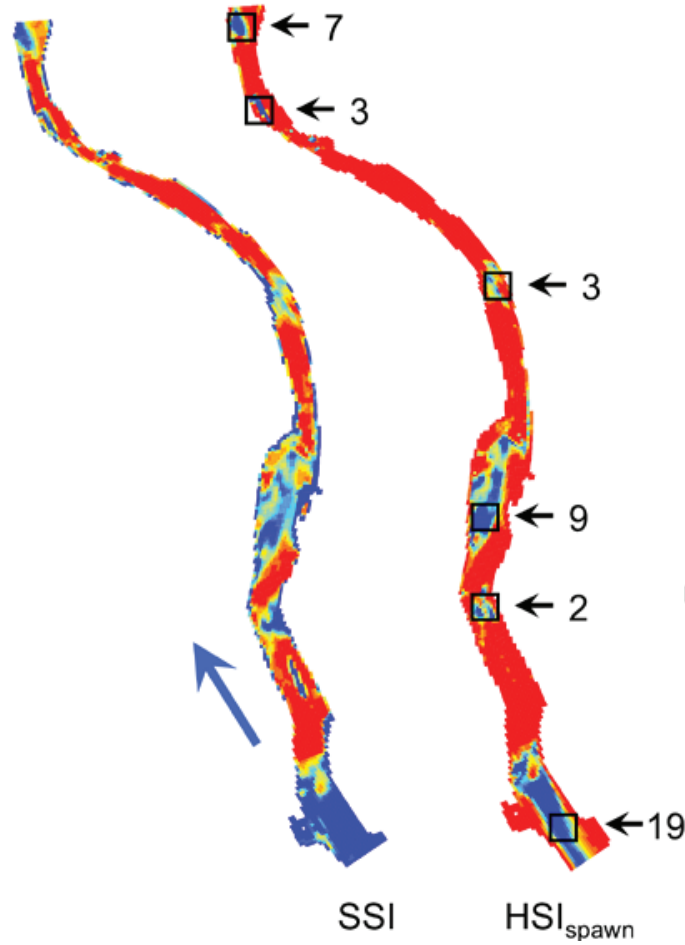

spawning period 2010

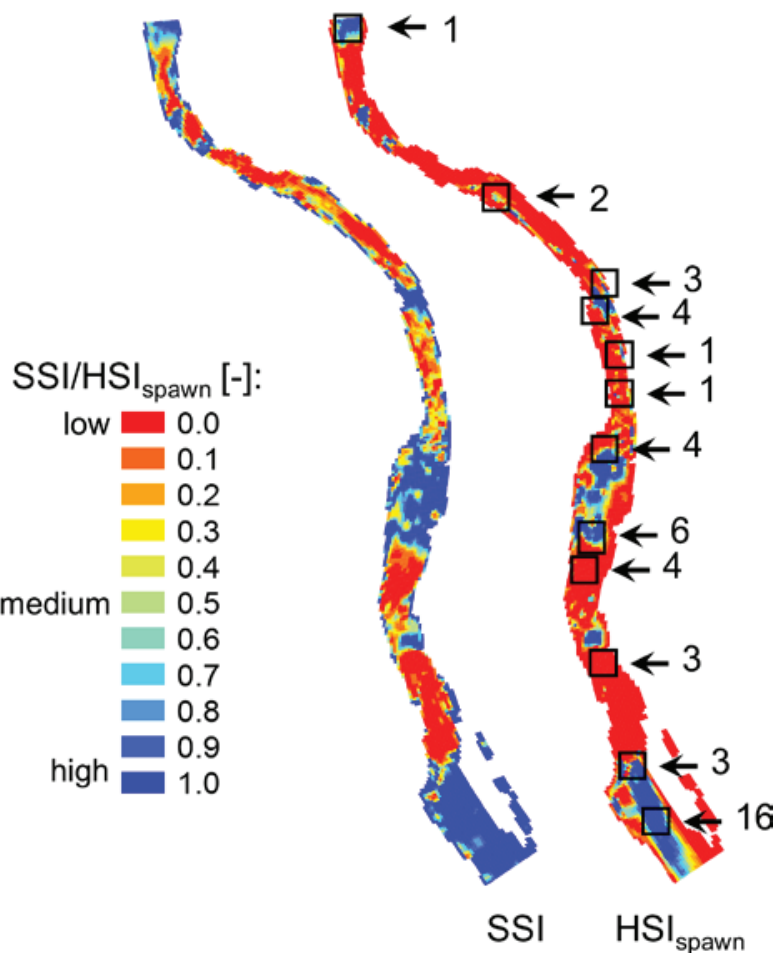

Figure 5 - Spatial distribution of the spawning sediment index (SSI) and spawning habitat suitability index (HSI ${ }_{\text {spann }}$ ) for the spawning periods in 2009 and 2010. In addition the observed spawning redds in each spawning period are listed.

similar duration but at different points in time. The flood in 2009 was much closer to the spawning period (September) than the flood in 2010 (July). For detailed information about the numerical simulations refer to Noack (2012).

\section{Results}

\section{Habitat variables}

Figure 4 presents the applied habitat variables in their spatial heterogeneity for the spawning period 2009. These habitat variables represent a typical situation during the spawning period in 2009 with regulated flow.

The spatial distribution visualized in Figure 4 indicates wide areas of less than $10 \%$ for the sand fraction. In pool areas where fine sediments can accumulate, values exceed $20 \%$. The spatial distribution of the gravel fraction shows a wide range of different amounts from less than $10 \%$ to more than $60 \%$. However, in the spawning areas SA1-SA4, the variation of gravel is not that high, ranging from 30\% to $40 \%$, mainly allocated to the membership function medium and partly to the high membership function. The pebble fraction is marked by lower variations for the whole study site, while the variation in the spawning areas is similar, ranging from $35 \%$ to $45 \%$. These values are within the membership function medium. The spatial distribution of cobbles allows a clear identification of the riffle areas where percentages of more than $60 \%$ are observed, while in between considerably lower percentages from $15 \%$ to $30 \%$ are identified.

In terms of hydraulic parameters the spawning areas SA1-SA4 are characterized by very shallow water depths, ranging mainly from $0.10 \mathrm{~m}$ to $0.40 \mathrm{~m}$, that are not critical for spawning. The preferred flow velocities range from $0.20 \mathrm{~m} / \mathrm{s}$ to $0.55 \mathrm{~m} / \mathrm{s}$ and are widely found in the study area. Those flow velocities are part of the low and medium membership function, whereas medium flow velocities are more suitably compared to low flow velocities. A similar analysis can be performed for the spatial distributions of input parameters in the spawning period 2010 which is not presented here.

Spawning sediment index (SSI) and spawning habitat suitability ( $\mathrm{HSI}_{\text {spawn }}$

The two-stage multivariate fuzzy-logical approach implemented in the habitat modelling software CASiMiR - runs through the entire set of fuzzy rules for each element of the numerical grid and computes an SSI and a HSI ${ }_{\text {spawn }}$ value with identical fuzzyfication and fuzzy rules for both spawning seasons. Figure 5 illustrates the obtained simulation results for both fuzzy steps (SSI, HSI spawn $_{\text {) }}$ in both spawning periods (2009, 2010). To verify the spatial distribution of spawning habitat suitability, they are compared to the observed redds in 2009 and 2010. The observed redds are marked by black squares while the attached number gives the number of counted redds in this location. 
Sediment spawning index (SSI)

In 2009 a very high SSI value is simulated for the spawning area SA1 which is roughly characterized by a low amount of sand $(<5 \%)$, a medium amount of gravel $(35 \%)$ and pebbles $(45 \%)$ and a low amount of cobbles $(15 \%)$. Compared to the preferred ranges in Table 1, this composition provides more or less ideal conditions for spawning for brown trout. The riffle area downstream of SA1 is not suitable because of the high amounts of cobbles $(>60 \%)$ which a spawning fish cannot move during redd digging. At SA2 the SSI values are marked by a higher diversity, providing sizeable areas with SSI values in the range of medium to very high. Near SA3 most areas are not suitable except for one patch located in the left bend of the study site. Upstream of SA4, the SSI is also not suitable given the typically high amount of cobbles and large boulders $(>60 \%)$ in this riffle area. At SA4 only the most downstream area provides values in the range of low and bigh SSI classes. The area upstream is not suitable because of a large pool where high amounts of sand are deposited.

The SSI values in the spawning period 2010 show a similar spatial distribution to the spawning period 2009. Differences are identified at SA2 with more areas in the very high range and in SA3, which is characterized by patches of different sizes with mostly SSI values in the low and medium range, but also single patches with bigh and very bigh SSI values.

Habitat suitability index for spawning ( $\left.\mathrm{HSI}_{\text {spawn }}\right)$

For the spawning period 2009 a strong dominance of the SSI values are indicated in Figure 5, as the spatial distribution of suitable and not suitable HSI values are very similar to the simulated SSI values. However, the extent of the areas with low SSI values is considerably reduced by the hydrodynamic variables which are required to maintain manoeuvrability for the spawning process. This aspect is recognizable predominantly for SA1 and SA2 as well as to a minor extent for SA4. The reductions concern mainly areas close to the river banks with low and very low flow velocities and water depths which limit the values of HSI $I_{\text {spawn }}$. The simulation result of the spawning period 2010 confirms the dominant behaviour of the sediment characteristics in simulating spawning habitat qualities. The patchy distribution of SSI values in SA3 is also reflected in the distribution of $\mathrm{HSI}_{\text {spawn }}$, although the area of the patches is considerably reduced by the hydrodynamic variables. For this area this is mainly due to bigh and very high flow velocities $(>0.8 \mathrm{~m} / \mathrm{s})$ where it is difficult for spawning brown trout to hold their position over the redd.

\section{Comparison to observed spawning redds}

Comparing the simulated spawning habitat qualities of CASiMiR to the mapping results of the natural spawning redds, a good approximation is indicated for the spawning season 2009 (Figure 5). Almost all observed redds (totally 43) are located in areas with

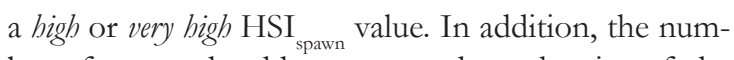
ber of counted redds corresponds to the size of the suitable spawning areas (e.g. in SA1 and between SA1 and SA2). The locations of the mapped redds in 2010 (totally 48) are distributed more evenly over the entire study area. A comparison with the simulated spawning habitat qualities in 2010 confirms the functionality of CASiMiR to simulate the selection of spawning sites for brown trout. Next to the same spawning areas in 2009, the additionally simulated patches with bigh and very high values of HSI $_{\text {spawn }}$ were actually selected for spawning in 2010. This can, for example, be indicated for the two redds upstream of SA4 and for the patchy characteristic in SA3.

\section{Discussion}

Based on the analysis of spawning habitat suitability in the River Spoel, the spawning period 2009 shows that $19 \%$ of the study site presents very bigh and bigh HSI $_{\text {spawn }}$ values, while in 2010, 23\% of the study site consists of suitable habitat conditions. The high quality of simulated HSI $_{\text {spawn }}$ corresponds to the observed total number of redds (2009: 43 redds; 2010: 48 redds). Moreover, the simulated and observed areas where spawning is barely possible confirm the high performance of the simulation approach. However, as no information about the exact dimensions of the suitable spawning areas is available, only a visual comparison (Figure 5) is feasible. Based on the analysis of the simulated habitat qualities for spawning and the comparison with observed natural redds, it can be stated that the predefined fuzzy sets and fuzzy rules approximate the habitat requirements of brown trout for the selection of spawning sites well (over 80\% of all counted redds are located in very high and high HSI $_{\text {spawn }}$-classes).

The presented modelling approach focuses on the spawning process and does not try to simulate survival over the whole reproduction process, since many other variables, such as dissolved oxygen, gravel permeability and biogeochemical processes would be required (Noack 2012). Compared to existing habitat modelling approaches, which are using a single parameter to describe sediment characteristics, the major advantage of the two-stage fuzzy approach is that it accounts for specific habitat requirements related to specific particle size classes. Because only limited information about the required percentages of certain particle size classes is available in the scientific literature, the imprecise approach of fuzzy logic is well suited to describe the sediment characteristics. Three membership functions with high overlapping ranges are chosen to describe the sediment characteristics, indicating a high degree of fuzziness, while for the hydrodynamic variables (water depth, flow velocity) five membership functions are applied. The higher number of membership functions with lower overlapping ranges increases precision because profound knowledge about hydro- 
dynamic preferences is available, assembled from experiences in fish habitat modelling over decades (Souchon \& Capra 2004).

Regarding the choice of habitat variables, additional habitat attributes might influence the spawning habitat qualities. For instance, the availability of cover and shelter would be an important aspect (Allouche 2002). However, according to local fish biologists, the availability of cover is not significant in the River Spoel because of the lack of predators and the constant flows during spawning. Other factors, such as competition between spawning fish and superimposition in the available space of spawning areas, cannot yet be implemented in habitat modelling techniques and is certainly an aspect that should be considered in future research (Gortázar et al. 2012).

Although a very satisfying performance of the proposed modelling approach can be seen in Figure 5, some observed redds are located in areas with low HSI values. This is likely to stem from uncertainties in the 3D-numerical modelling of the required input variables. Although the numerical model is thoroughly calibrated and validated, not all hydromorphological characteristics may be reproduced correctly in terms of their spatial distribution because of the limited spatial resolution of sediment samples. Slight variations of the relevant input parameters for the habitat modelling may thus occur, resulting locally in poorer model performance. However, the primary aim of artificial flooding, which is to improve and maintain ecological integrity by creating dynamic spawning habitat patches (Scheurer et al. 2003), is achieved by the numerical modelling, especially with regard to required bed alterations and renewal of substrate conditions.

\section{Conclusions}

The presented modelling approach aims to simulate the selection of spawning sites for brown trout by considering multiple particle size classes to address sediment-specific habitat requirements during spawning by using a two-stage fuzzy-logical approach. In particular, the consideration of classified particle size distributions allows accounting for required amounts of fine sediments and the maximum movable particle size during redd digging, which cannot be considered using single sediment indices. Especially in Alpine areas the predictability of the habitat modelling approach, in combination with the numerical sedimenttransport model, further allows investigating ecological flood management scenarios (variations in the number, timing, magnitude and duration of artificial flooding) by simulating the effects of changed abiotic characteristics on the availability of suitable spawning habitats for brown trout.

\section{References}

Allouche, S. 2002. Nature and functions of cover for riverine fish, Bulletin Francais de la Peche et de la Pisciculture 365/366: 297-324.

Armstrong, J.D., P.S. Kemp, G.J.A. Kennedy, M. Ladle \& N.J. Milner 2003. Habitat requirements of Atlantic salmon and brown trout in rivers and streams. Fisheries Research 62: 143-170.

Beyer, H.L., D.T. Haydon, J.M. Morales, J.L. Frair, M. Hebblewhite, M. Mitchell \& J. Matthiopolos 2010. The interpretation of habitat preference metrics under use-availability designs. Philosophical Transaction of the Royal Society 365: 2245-2254.

Conallin, J., E. Boegh \& J. Jensen 2010. Instream physical habitat modelling types: an analysis as stream hydromorphological modelling tools for EU water resource managers. Journal of River Basin Management 8: 93-107.

Dirksmeyer, J. \& E. Brunotte 2009. Sediment textures and hydrogeomorphological characteristics of salmon and sea trout spawning habitats in Germany: A contribution to river ecology. Zeitschrift fuer Geomorphologie 53(3): 319-334.

Fluskey, R.D. 1989. An analysis of the gravels used by spawning salmonids in Ireland. Irish Fisheries Investigation Series A (Freshwater) 32: 1-14.

Gortázar, J., C. Alonso \& D. García de Jalón (2012). Brown trout redd superimposition in relation to spawning habitat availability. Ecology of Freshwater Fish 21: 283-292.

Heggenes, J. 1988. Substrate preferences of brown trout fry (Salmo trutta) in artificial stream channels. Canadian Journal of Fish and Aquatic Science 45: 1801-1806.

Kondolf, G.M. \& M.G. Wolman 1993. The sizes of salmonid spawning gravels. Water Resources Research 29: 2275-2285.

Kondolf, G.M., P. Angermeier, K. Cummins, T. Dunne, M. Healey, W. Kimmerer, P.B. Moyle, D. Murphy, D. Patten, Railsback, D. Reed, R. Spies \& R. Twiss 2008. Prioritizing river restoration: Projecting cumulative benefits of multiple projects: an example from the Sacramento-San Joaquin River system in California, Environmental Management 42: 933-945.

Leclerc, M.A., A. St-Hilaire \& J.A. Bechara 2003. State-of-the-art and perspectives on habitat modelling. CanadianWater Resources Journal 28(2): 153-172.

Louhi, P., A. Maeki-Petaeys \& J. Erkinaro 2008. Spawning habitat of Atlantic salmon and brown trout: general criteria and intragravel factors. River Research and Applications 24: 330-339.

Moir, H.J., C.N. Gibbins, C. Soulsby \& A.F. Youngson 2005. PHABSIM modelling of Atlantic salmon spawning habitat in an Upland stream: testing the influence of habitat suitability Indices on model output. River Research and Applications 21: 1021-1034.

Mouton, A.M., M. Schneider, A. Peter, G. Holzer, R. Müller, P.L.M. Goethals \& N. De Pauw 2008. Optimisation of a fuzzy physical habitat model for spawn- 
ing European grayling (Thymallus thymallus L.) in the Aare river (Thun, Switzerland). Ecological Modelling 215(1-3): 122-132.

Mull, K.E. \& M.A. Wilzbach 2007. Selection of spawning sites by coho salmon in a northern California stream, North American Journal of Fisheries Management 27: 1343P.L.M.1354.

Noack, M. 2012. Modelling approach for interstitial sediment dynamics and reproduction of gravelspawning fish. Dissertation, Mitteilungen des Instituts für Wasser- und Umweltsystemmodellierung, Heft 214, Universität Stuttgart, Stuttgart.

Noack, M., M. Schneider \& S. Wieprecht 2013. The Habitat Modelling System CASiMiR: A Multivariate Fuzzy Approach and its Applications. In: Maddock, I., A. Harby, P. Kemp \& P. Wood (eds.), Ecohydraulics: an integrated approach: 71-95.

Olsen, N.R.B. 2013. SSIIM Users’ Manual. Version January 2013. The Norwegian University of Science and Technology. Available at: http:// folk.ntnu.no/nil$\mathrm{sol} / \mathrm{ssiim} /$ manual4.pdf.

Ortlepp, J. \& U. Muerle 2003. Effects of experimental flooding on fishes: The River Spoel, Swiss National Park. Aquatic Sciences, Research Across Boundaries 65: 232-238.

Scheurer, T. \& P. Molinari 2003. Experimental Floods in the River Spoel, Swiss National Park: Framework, Objectives and Design. Aquatic Sciences, Research Across Boundaries 65: 183-190.

Schneider, M. 2001. Habitat- und Abflussmodellierung für Fließgewässer mit unscharfen Berechnungsansätzen. Disseration, Mitteilungen des Instituts für Wasser- und Umweltsystemmodellierung, Heft 108, Universität Stuttgart, Stuttgart.

Schneider, M., I. Kopecki, A. Eisner \& M. Noack 2007. Linking morphodynamic and fish habitat modelling - Case Study Bodendorf, River Mur (Austria). $32^{\text {th }}$ IAHR Congress, Venice, Italy.

Souchon Y. \& H. Capra 2004. Aquatic habitat modelling: biological validations of IFIM/Phabsim meth- odology and new perspectives. Hydroécologie Appliqueé 14: 9-25.

Soulsby, C., A.F. Youngson, H.J. Moir \& I.A. Malcom 2001. Fine sediment influence on salmonid spawning habitat in a lowland agricultural stream: a preliminary assessment. The Science of the Total Environment, 265(1-3): 295-307.

Wooster, J.K., S.R. Dusterhoff, Y. Cui, L.S. Sklar, W.E. Dietrich \& M. Malko 2008. Sediment supply and relative size distribution effects on fine sediment infiltration into immobile gravels. Water Resources Research 44: W03424.

\section{Authors}

\section{Markus Noack}

is Head of the Hydraulic Laboratory of the Institute for Modelling Water and Environmental Systems at the University of Stuttgart. Next to experimental research, his primary interest is in the interaction between river morphology and ecology. Email: markus. noack@iws.uni-stuttgart.de

\section{Johannes Ortlepp}

is a biologist specializing in general river ecology. He has worked on the River Spoel since 1995, focusing on the effects of experimental flooding on aquatic species. Hydra - Büro für Gewässerökologie Mürle \& Ortlepp, Öschelbronn, Germany. Email: j.ortlepp@ hydra-institute.com

\section{Silke Wieprecht}

is Professor at the University of Stuttgart and Director of the Institute for Modelling Water and Environmental Systems and Head of the Department Hydraulic Engineering and Water Resources Management. Email: wieprecht@iws.uni-stuttgart.de 